SVU-International Journal of Veterinary Sciences: 1(1): 4-15, 2018.

Print ISSN: 2535-1826

Online ISSN: 2535-1877

Review Article

Open Access

\title{
Liver Regeneration and New Technical Possibilities by Two-photon Based Intravital Imaging
}

\begin{abstract}
Ahmed Ghallab ${ }^{1,2}$ and Jan G. Hengstler ${ }^{1}$
${ }^{1}$ Leibniz Research Centre for Working Environment and Human Factors at the Technical University Dortmund, Dortmund, Germany. ${ }^{2}$ Department of Forensic Medicine and Toxicology, Faculty of Veterinary Medicine, South Valley University, Qena, Egypt.
\end{abstract}

\begin{abstract}
One of the outstanding features of the liver is its enormous regeneration capacity. Compared to other solid organs, such as kidney, heart or brain, the liver shows a superior capacity to regenerate. Probably, this regeneration capacity has evolved during 'animal plant warfare', when plants protected themselves from herbivores by new toxins and herbivores responded by novel detoxifying enzymes and efficient hepatic regeneration. Control mechanisms of liver regeneration have attracted scientists since decades. One limitation that has hampered progress is the lack of possibilities of real-time observations of cellular and subcellular processes in the regenerating liver without removing the organ for analysis. This has now become possible by the introduction of an improved technology of two-photon based intravital imaging. This technology allows the possibility to perform real-time imaging of the intact liver in anesthetized mice. Resolution is close to the theoretically possible $200 \mathrm{~nm}$ and therefore allows imaging of organelles and vesicles. Also, imaging of fast processes in the millisecond range is possible. Using available fluorescent reporter mouse systems, it is possible to visualize all resident cell types of the liver, such as hepatocytes, Kupffer cells, stellate cells and sinusoidal endothelial cells. Furthermore, infiltrating immune cells can be imaged during liver injury and regeneration using cell-specific antibodies or reporter mice. This minireview presents some of the possibilities of intravital imaging and its applicability for research in the field of liver regeneration.
\end{abstract}

Received: June 3, 2018

Accepted: June 3, 2018

Published: June 30, 2018

*Corresponding Author: Ahmed Ghallab

E-mail: Ghallab@ifado.de

Citation: Ghallab and Hengstler, 2018. Liver Regeneration and New Technical Possibilities by Two-photon Based Intravital Imaging. SVU-IJVS, 1 (1): 4-15.

Copyright: This is an open access article distributed under the terms of the creative common attribution license, which permits unrestricted use, distribution and reproduction in any medium provided the original author and source are created.

Competing interest: The authors have declared that no competing interest exists. 
Liver regeneration as an evolutionary consequence of 'animal plant warfare'.

The liver fulfils several vital functions of which the most important are secretion of proteins, such as albumin, coagulation factors and plasma carrier proteins, detoxification of exogenous and endogenous toxins, regulation of lipid and carbohydrate metabolism and bile synthesis needed for absorption of lipophilic nutrients (Michalopoulos, 2007). Nutrients and xenobiotics absorbed from the intestine enter the liver via the portal vein and pass sheets of hepatocytes before they enter the systemic circulation. This strategic location allows function as a pre-processor of absorbed food constituents and a barrier against toxic xenobiotics (Michalopoulos, 2007, Michalopoulos and DeFrances, 1997). An outstanding feature of the liver is its enormous regeneration and detoxification capacity. This has evolved some 200-400 million years ago, when several species that originally evolved in the see started to populate the land and to live on plants. To protect from herbivores plant toxins evolved. Herbivores responded with the expression of detoxifying enzymes and the optimization of the regeneration machinery to protect themselves from liver loss by food toxins. Therefore, the current complex and well-orchestrated phenomenon of liver regeneration is to a large part the result of an evolutionary process generally named 'animal plant warfare'.

\section{Types of damage and regeneration responses.}

One of the most frequently used experimental methods of liver regeneration is the carbon tetrachloride $\left(\mathrm{CCl}_{4}\right)$ system. High doses of $\mathrm{CCl}_{4}$ (e.g. $1 \mathrm{~g} / \mathrm{kg}$ in mice) kill a central fraction of hepatocytes which amount to approximately $40 \%$ of the liver mass (Fig. 1). This pericentral damage regenerates within 8 days in a wellorchestrated, highly reproducible process (Ghallab et al., 2016, Hoehme et al., 2010, Hohme et al., 2007, Schliess et al., 2014). The high degree of inter-mouse reproducibility, higher than that of most other chemicals, made the $\mathrm{CCl}_{4}$ system so popular. Formerly used in the cleaning industry and fire extinguishers, $\mathrm{CCl}_{4}$ has been banned as an industrial chemical but serves as an experimental standard in hepatology. It shows a high degree of similarity to paracetamol (acetaminophen, APAP) induced hepatotoxicity (Gunawan et al., 2006). APAP-induced hepatotoxicity is the most common cause of acute liver failure in Europe and the United states (Gunawan et al., 2006, Lee et al., 2007). Both, $\mathrm{CCl}_{4}$ and APAP are metabolically activated by cytochrome P4502E1 (CYP2E1) which is expressed only by a pericentral fraction of hepatocytes (Fig. 2). Therefore, the damage pattern and consequently the time course of regeneration are similar. When using the $\mathrm{CCl}_{4}$ system in analogy to APAP intoxication, one should bear in mind, also the differences between both compounds: APAP is converted by CYP2E1 to its toxic metabolite $\mathrm{N}$-acetyl-p-benzoquinoneimine (NAPQI) (Fig. 3). NAPQI irreversibly binds to the sulfhydryl group of reduced glutathione (Gunawan et al., 2006, Woolbright and Jaeschke, 2017). When GSH is depleted below critical thresholds binding of NAPQI to protein targets and/or oxidative stress are responsible for cell killing. In contrast to NAPQI with its preferential GSH depletion the metabolites of $\mathrm{CCl}_{4}$ preferentially cause lipid peroxidation (Weber et al., 2003). CYP2E1 metabolises $\mathrm{CCl}_{4}$ to highly reactive free radical metabolites, particularly trichlormethyl and trichloromethyl peroxy free radicals which attack polyunsaturated fatty acids in membranes causing membrane disruption (Manibusan et al., 
2007). These differences in binding specificities of the reactive APAP and $\mathrm{CCl}_{4}$ metabolites lead to critical differences in early stress signalling (Gunawan et al., 2006). Knockdown or inhibition of c-Jun Nterminal kinase 1 (JNK1) strongly reduces hepatotoxicity of APAP. In contrast JNK inhibition does not provide protection against $\mathrm{CCl}_{4}$. Although the basic mechanisms are clear several aspects, for example the mechanism and extent of the contribution of non-parenchymal and immune cells to APAP and $\mathrm{CCl}_{4}$ induced hepatotoxicity still have to be elucidated (Jaeschke et al., 2002, Marques et al., 2015).
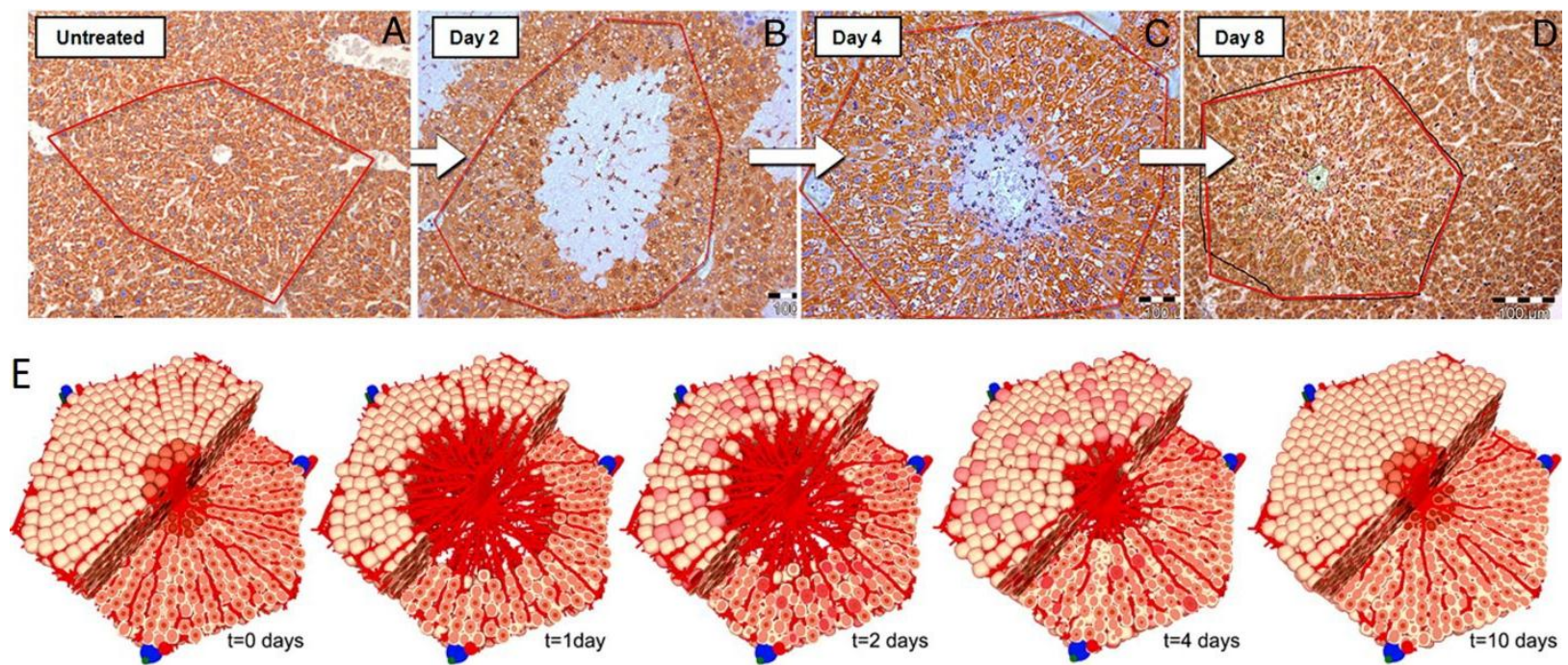

Fig. 1. Hepatoxicity caused by $\mathrm{CCl}_{4}$ in mouse livers. A-D. Induction of pericentral hepatocyte death (day 2) is followed by a regeneration phase that is complete after approximately eight days. E. Simulation of $\mathrm{CCl}_{4}$-induced liver damage and regeneration at the level of the liver lobule. The images are stills of a spatio-temporal mathematical model (from: Hoehme et al., 2010).

Besides hepatotoxic compounds partial hepatectomy is a frequently used technique to study liver regeneration (Michalopoulos, 2007, Michalopoulos and DeFrances, 1997). In a relatively simple operation specific liver lobes are removed. The remaining lobes enlarge and make up for the lost mass. The regeneration process takes five to seven days and proceeds in an orderly and highly reproducible fashion that has already been carefully reviewed previously (Michalopoulos, 2007, Michalopoulos, 2010).

\section{Organ, lobule and cell scale of liver regeneration.}

The regenerative response takes place at the organ, lobule as well as the cellular and subcellular scale. At the organ level the precise control of liver weight is striking (Michalopoulos and DeFrances, 1997). Not only $2 / 3$ hepatectomy but also smaller resections of less than $10 \%$ are followed by precise restoration of the initial liver weight. After transplantation of livers from large into small dogs liver size decreases and adapts to the new body size (Francavilla et al., 1988). Vice versa, baboon livers rapidly increase in weight when transplanted into humans (Michalopoulos and DeFrances, 1997, Starzl et al., 1992). 


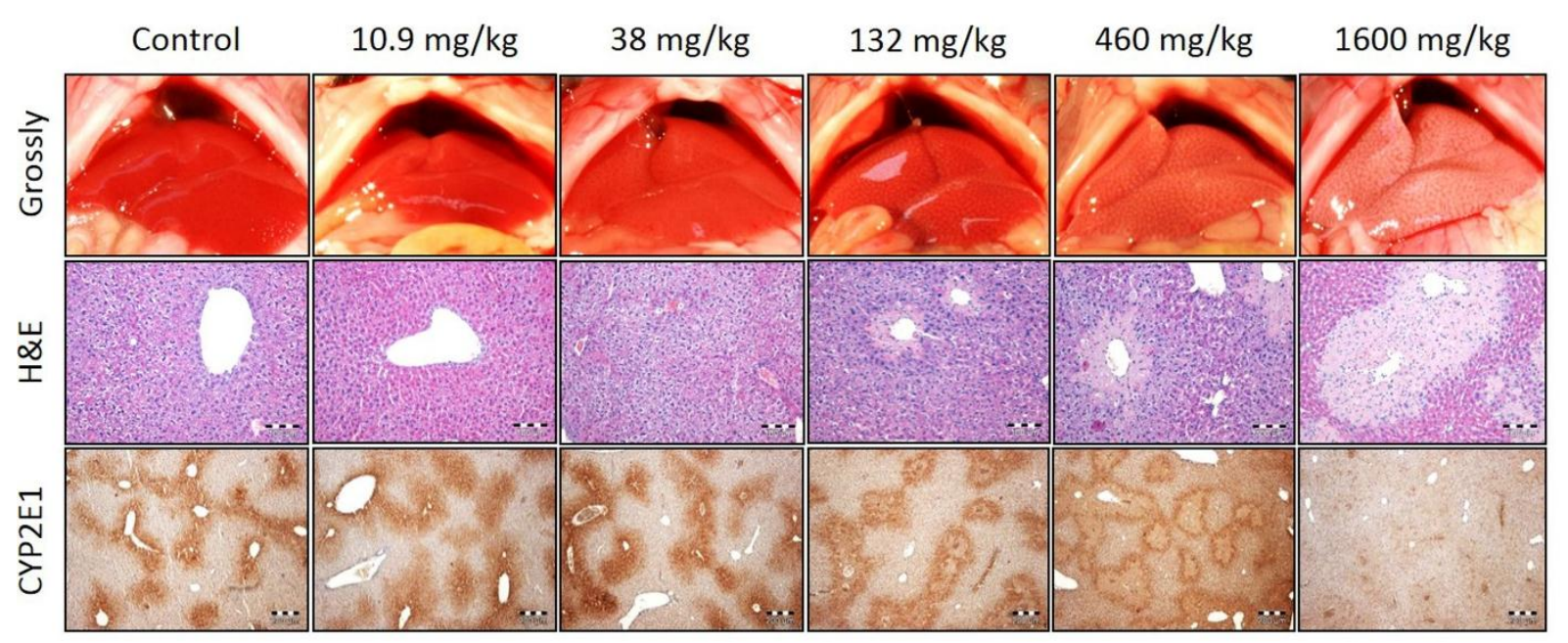

Fig. 2. Relationship of CYP2E1 expression and $\mathrm{CCl}_{4}$-induced hepatotoxicity in mouse livers. Male C57BL/6N mice received various intraperitoneal injections of $\mathrm{CCl}_{4}$. After $24 \mathrm{~h}$, hematoxylin and eosin (HE) staining as well as immunostaining using antibodies directed against CYP2E1 were performed in liver tissue. The control shows the typical pattern of pericentral CYP2E1 expression. After administration of $1.6 \mathrm{~g} / \mathrm{kg}$ the total CYP2E1 positive area was destroyed. At lower doses only the central fraction of the CYP2E1 positive area becomes necrotic because it expresses higher CYP2E1 levels compared to the outer part of the CYP2E1 positive area. In contrast, the CYP2E1 negative periportal region does not show any signs of toxicity even after the highest tested dose (from: Ghallab et al., 2016).

At the lobule scale the regenerative process depends on the type of liver damage. After hepatotoxic damage to the central fraction of hepatocytes $\left(\mathrm{CCl}_{4}\right.$ or APAP) some of the surviving peripheral hepatocytes proliferate and the dead cell area is closed in a six days process (Fig. 1). Two organisation principles are critical during regeneration to guarantee functional lobule architecture. First, the microvessel or sinusoidal endothelial cell network guides liver regeneration. Iterative mathematical modelling and experimental work has demonstrated that hepatocytes align in the direction of the closest sinusoid and that this mechanism is necessary for the spatiotemporal regeneration process (Hoehme et al., 2010). Later is has been shown that sinusoidal endothelial cells communicate with hepatocytes by the key cytokines HGF and Wnt 2 which also play critical roles in inducing the synchronized wave of regenerative hepatocyte proliferation (Ding et al., 2010). Second, the bile canalicular network established by the apical domains of the hepatocytes is critical for lobule architecture as well as hepatotoxicity. Recently, in vivo imaging with two-photon microscopy provided evidence that APAPinduced apical membrane rupture followed by flooding of the hepatocyte with bile which represents an irreversible step leading to hepatocyte death, whereas rupture of the basolateral membrane at the sinusoidal domain is reversible and may be survived (Li et al., 2011). In contrast to the situation after $\mathrm{CCl}_{4}$ or APAP intoxication a different scenario is observed following partial hepatectomy. To make up for the mass of the removed tissue the lobules in the remaining lobes increase. Therefore, about seven days after hepatectomy lager 
lobules can be found. It would be plausible that in the following weeks novel lobules are formed which then allows reduction of the size of individual lobules to normal levels. However, this has not yet been
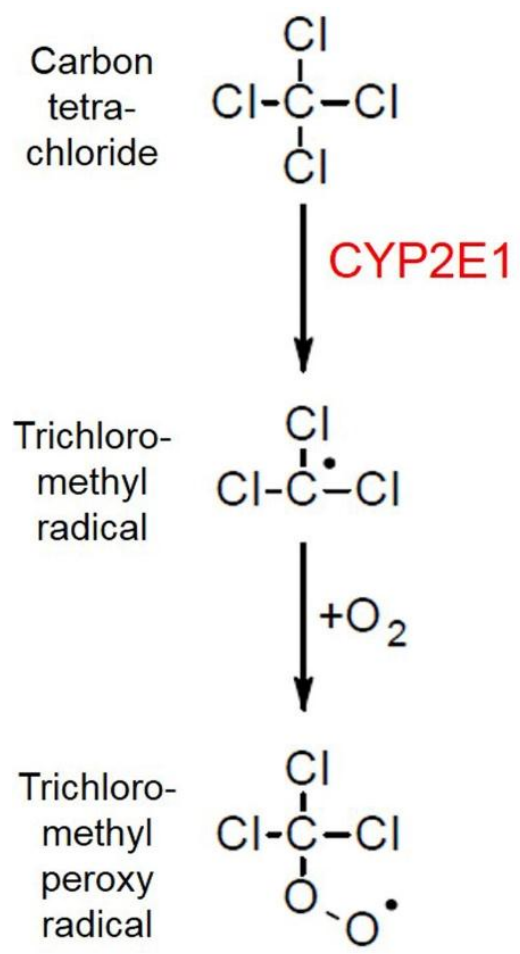

studied systematically. One of the most critical processes that have to be accomplished at the cellular scale is polarity establishment.<smiles>CC(=O)Nc1ccc(O)cc1</smiles><smiles>CC(=O)N=C1C=CC(=O)C=C1</smiles>

Fig. 3. Metabolic activation of $\mathrm{CCl}_{4}$ and paracetamol by cytochrome P450 2E1 (CYP2E1).

When hepatocytes divide, a novel apical domain and bile canalicular branch has to be established between the daughter hepatocytes. This can be observed both, after partial hepatectomy as well as after toxic liver damage. Relatively little is known how hepatocytes establish cell polarity. Most of our knowledge stems from model cell systems, such as canine kidney cells (MDCK), drosophila or yeast (Cohen et al., 2004, Martin-Belmonte and Mostov, 2008, McCaffrey and Macara, 2009, Panbianco and Gotta, 2011, Shivas et al., 2010, Wang et al., 2009). A simplified schedule of the basic machinery that establishes cell polarity is given in Fig. 4 (review: Martin-Belmonte and Mostov, 2008): (i) Adherent and tight junctions are formed, usually triggered by cell-cell contact; (ii) Polarity complex proteins, usually including Par 3 localize to the tight junctions; (iii) PTEN localizes to the polarity complex proteins in the apical region. PTEN catalyzes the enrichment of phosphatidylinositol 4,5-bisphosphate at the apical domain and restricts phosphatidylinositol 3,4,5-trisphosphate to the basolateral membrane; (iv) PI3K may localize to the adherent junctions and support the presence of phosphatidylinositol 3,4,5 trisphosphate at the basolateral membrane; 
Phosphatidylinositol 4,5 bisphosphate at the apical membrane recruits and activates Cdc42, a process which can be supported by further factors (GEFs, Anx2, etc.). Active Cdc 42 in turn activates Par 6/aPKC and other polarity complexes that maintain the apical domain; (vi) Active Cdc 42 controls the actin cytoskeleton to mediate the exocytosis and fusion of a specialized organelle, the vacuolar apical compartment (VAC), with the plasma membrane to form the apical lumen; (vii) Anti-adhesive factors, such as large transmembrane glycoproteins or polysaccharides are expressed on the apical membrane to induce membrane detachment and a luminal space; (viii) A complex transport machinery is established that orchestrates the sorting of proteins to either the apical or the basolateral membrane. Studies on the complex molecular mechanism controlling hepacyte polarity but also polarity of other mammalian cells than hepatocytes have been difficult largely because of technical obstacles (Wang and Boyer, 2004). One limitation is that it is challenging to quantitatively separate apical and basolateral membranes for an unbiased analysis of the proteome and lipidome during the process of cell polarity establishment.

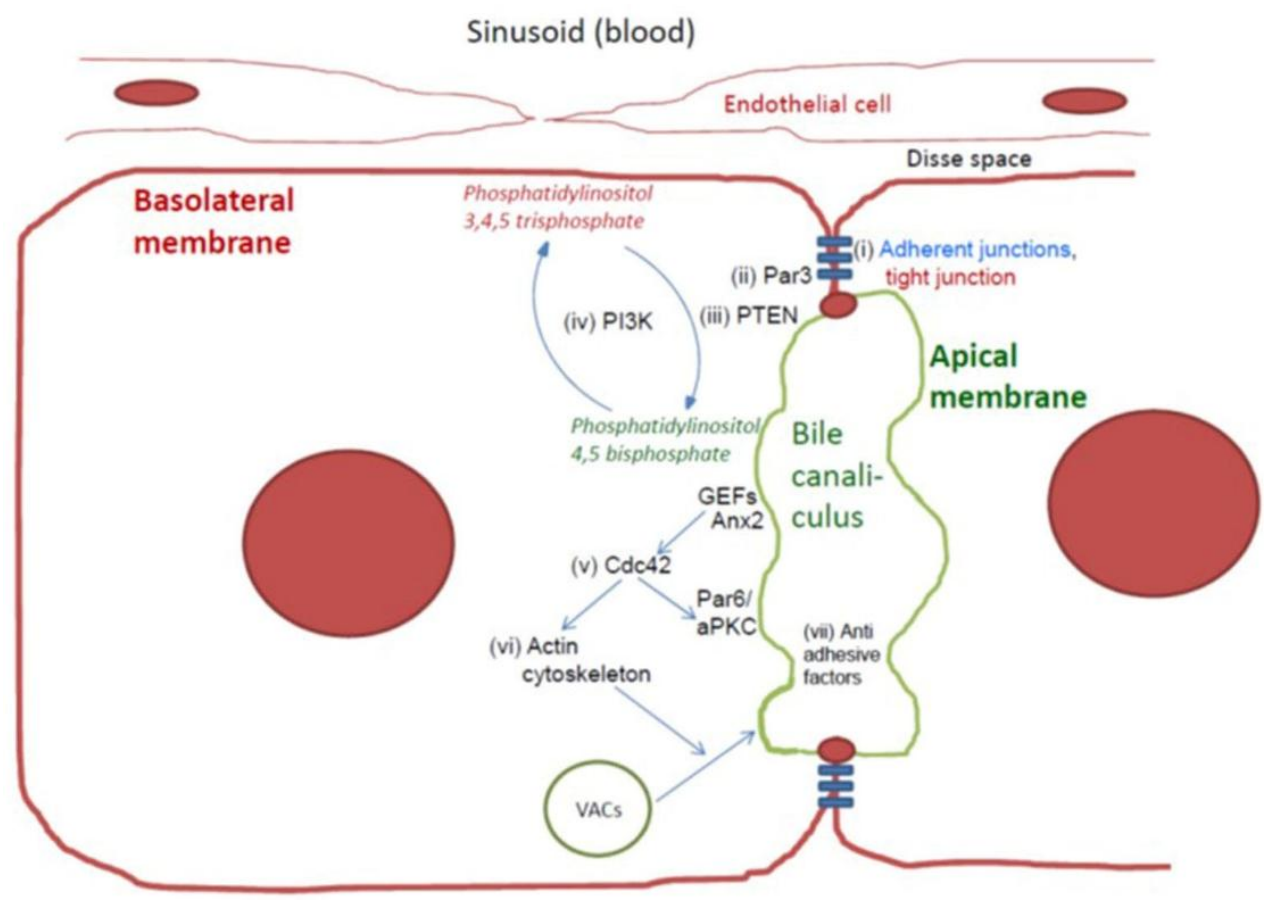

Fig. 4. Establishment of cell polarity.

\section{New analytical methods: two-photon based imaging}

Usually, analysis of time courses of liver damage and regeneration has been performed with fixed liver tissue prepared at different time intervals after intoxication or hepatectomy. However, recently a twophoton imaging toolbox has been introduced that allows the continuous intravital recording of intact organs of 
anesthetised mice with subcellular resolution (Jansen et al., 2017, Reif et al., 2017). The imaging setup consists of a twophoton infrared laser, long-distance objectives with high-numerical aperture, and particularly sensitive detectors. Moreover, a precisely adjusted inhalation anaesthesia and skilled animal preparation are required. A strength of this method is the possibility to image deeply in liver tissue. Moreover, it allows to study biological processes with fast kinetics, for example the transport of the fluorescent bile salt analogue cholyl-lysyl-fluorescein (CLF, Fig. 5). After bolus injection into the tail vein, CLF first appear in the sinusoids. Next it occurs at the margin of the hepatocytes, where it probably enriched in the intercellular space between endothelial cells and hepatocytes (space of Disse). Finally, CLF is transported into the hepatocytes and secreted into bile canaliculi.

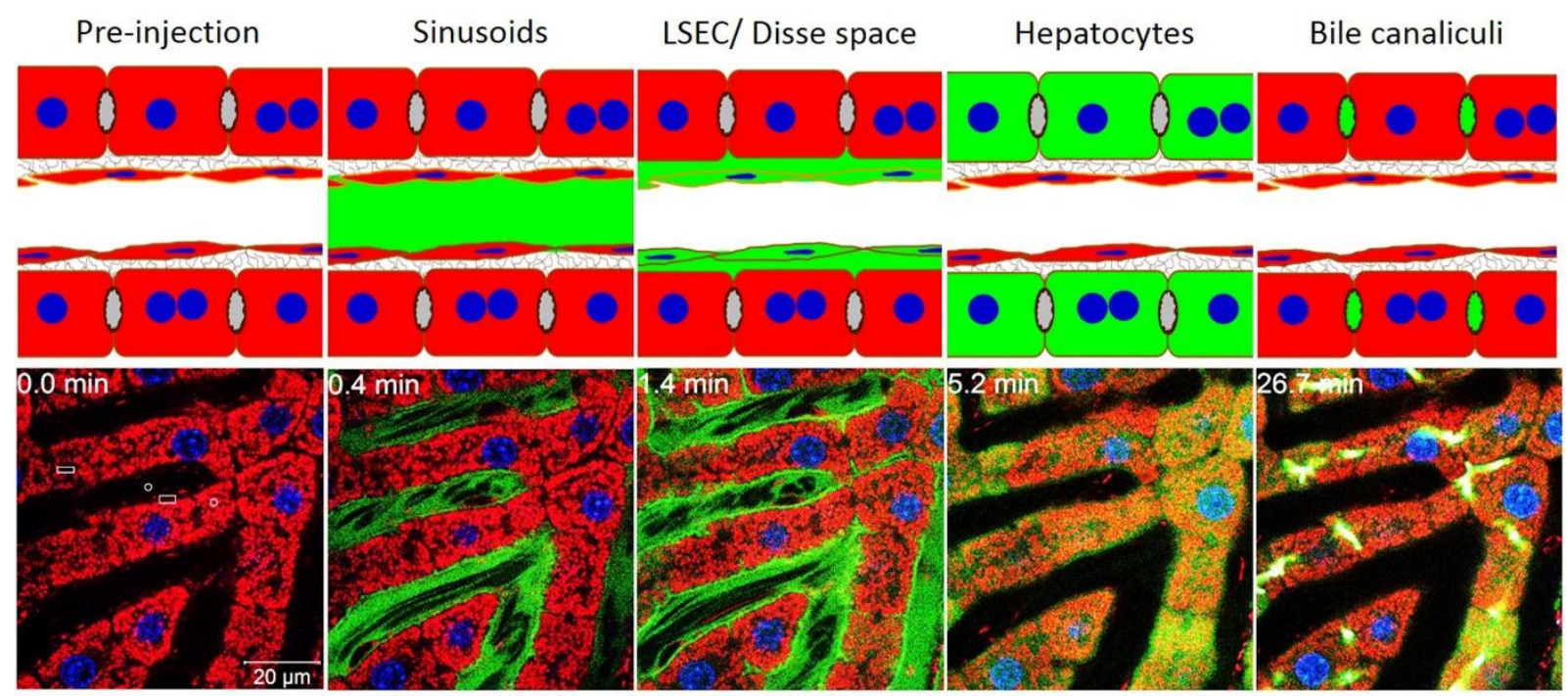

Fig. 5. Hepatic transport of the green fluorescent bile salt analogue CLF. The images are stills from a video showing CLF preferentially in the sinusoids, in sinusoidal endothelial cells (LSEC)/ space of Disse, in hepatocytes and in bile canaliculi (modified from: Reif et al., 2017).

A further possibility of intravital twophoton based imaging is that all resident cell types of the liver can be visualized. Liver tissue is composed of four resident cell types, (i) hepatocytes organized in sheets along microvessels, the sinusoids, (ii) sinusoidal endothelial cells (LSEC) lining the microvessles, (iii) Kupffer cells, the tissue resident macrophages of the liver, located at the blood side of LSEC, and (iv) stellate cells located in the space of Disse between the LSEC and hepatocytes (Fig. 6). A prerequisite for visualizing these cells are appropriate reporter mice producing fluorescence in target cell type. For this purpose, the $\mathrm{mT} / \mathrm{mG}$ mouse offers excellent opportunities (Reif et al., 2017). This mouse line contains a targeting vector encoding a floxed membrane-targeted tandem dimer Tomato sequence (mT), followed by a membrane-targeted green fluorescent protein (mG) (Muzumdar et al., 2007, Reif et al., 2017). In these mice all membranes show red fluorescence. Therefore, hepatocytes can be visualized by $\mathrm{mT} / \mathrm{mG}$ mice, although of course membranes of 
other cell types express red fluorescence (Fig. 7A). The $\mathrm{mT} / \mathrm{mG}$ mouse system serves also as a Cre reporter. Mating the $\mathrm{mT} / \mathrm{mG}$ mice with mouse strains expressing Cre recombinase under controls of tissuespecific promotors, leads to a switch to membrane targeted EGFP in the cells of interest, while the membranes of all other cell types remain red (Reif et al., 2017). Using mice expressing Cre recombinase under control of the lysozyme M (LysM) promotors allows visualization of Kupffer cells, infiltrating macrophages and granulocytes (Fig. 7B) (Clausen et al., 1999, Reif et al., 2017). Kupffer cells can be seen with their cell protrusions moving locally in the sinusoidal blood. Using the same principle mice expressing Cre recombinase under control of the Tie 2 promotor show green fluorescence in the sinusoidal endothelial cells (Fig. 7C) (Koni et al., 2001, Reif et al., 2017). Finally, expressing Cre under control of the Lrat promotor (Mederacke et al., 2013) allows visualization of stellate cells (Fig. 7D).
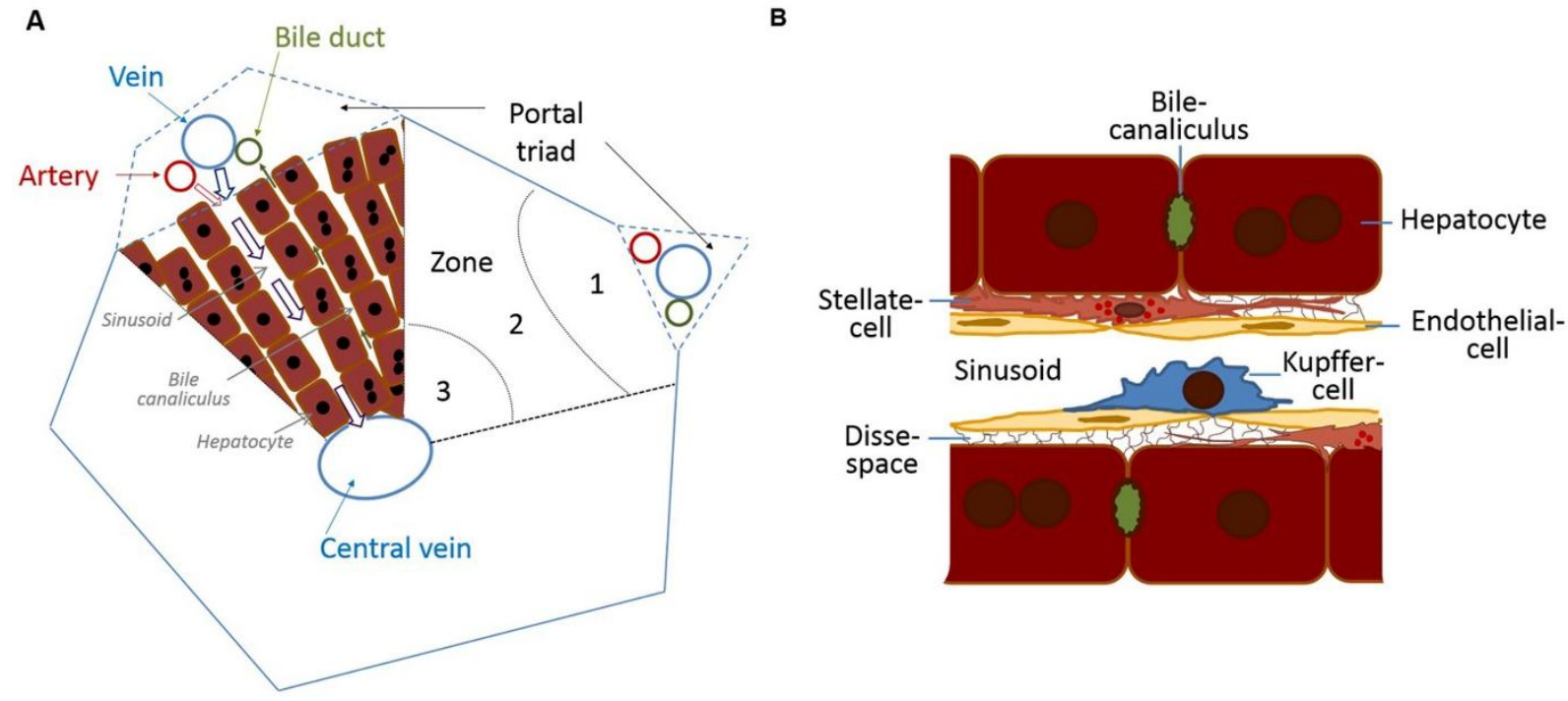

Fig. 6. Cell types of the liver. A. Organization of the liver lobule. B. Four resident cell types of the liver: hepatocytes, liver sinusoidal endothelial cells (LSEC), Kupffer cells and stellate cells.

Infiltrating immune cells play a critical role during liver injury and regeneration. They can be imaged either by i.v injection of specific antibodies or by using cell-specific reporter mice. For example, after induction of physical liver damage by high energy laser, an early response is infiltration of neutrophils into the dead cell area (Fig. 8). This example shows that destruction and regeneration processes can now directly be observed in intact living organs.
In conclusion, the introduction of twophoton based intravital imaging in its advanced form into hepatology research provides excellent opportunities to researchers to get deeper insights into disease pathogenesis. However, a systematic two-photon based analysis of liver regeneration has only just begun. 

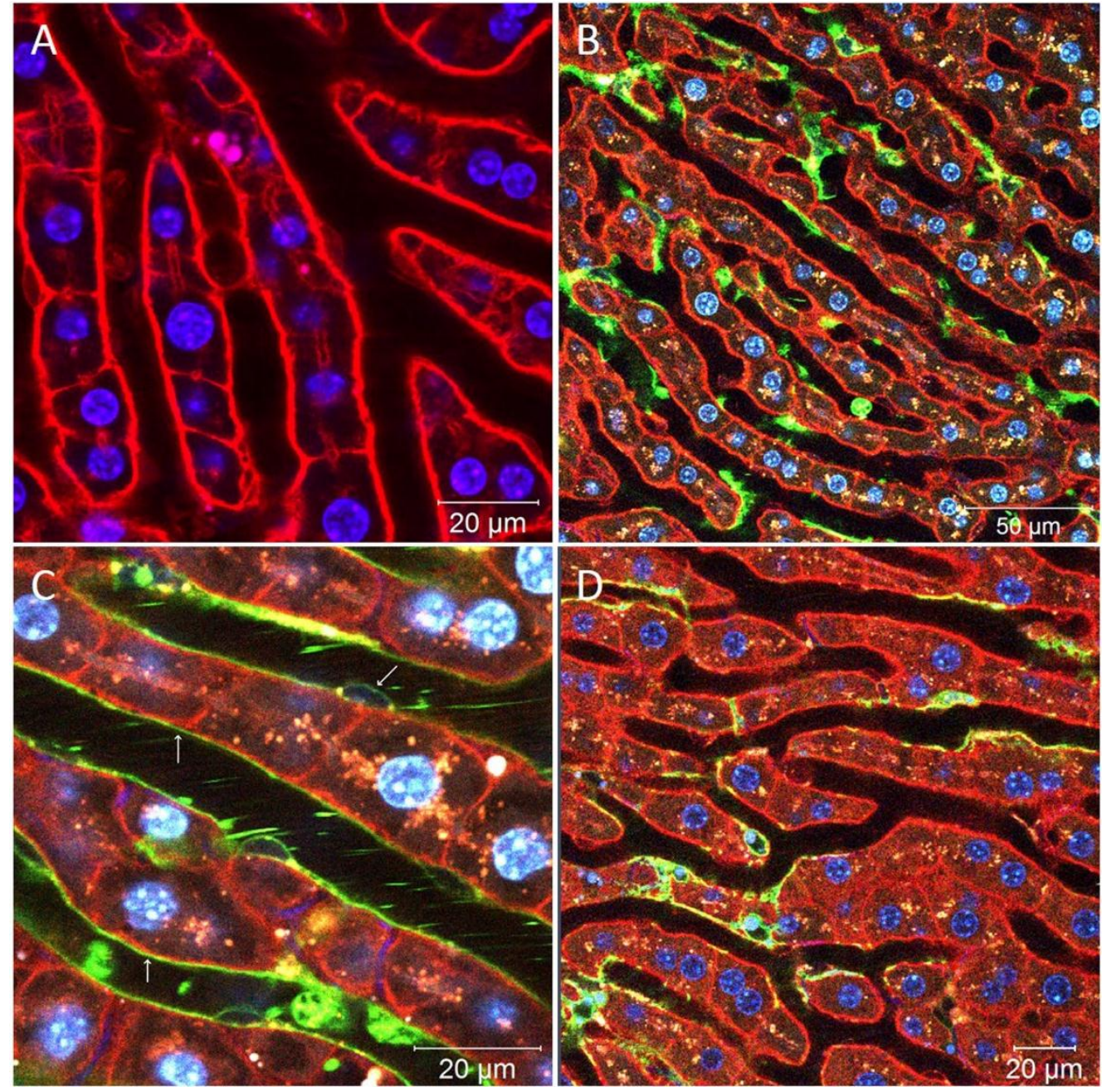

Fig. 7. Visualizing of the resident liver cells by the $\mathbf{m T} / \mathbf{m G}$ mouse system. A. Red membranes of $\mathrm{mT} / \mathrm{mG}$ mice in all cell types, here sheets of hepatocytes; $\mathbf{B}$. green fluorescence in Kupffer cells by mating to LysM-Cre mice; $\mathbf{C}$. green fluorescence in sinusoidal endothelial cells by mating to Tie-2-Cre mice; D. green fluorescence in stellate cells by mating to Lrat-Cre mice.

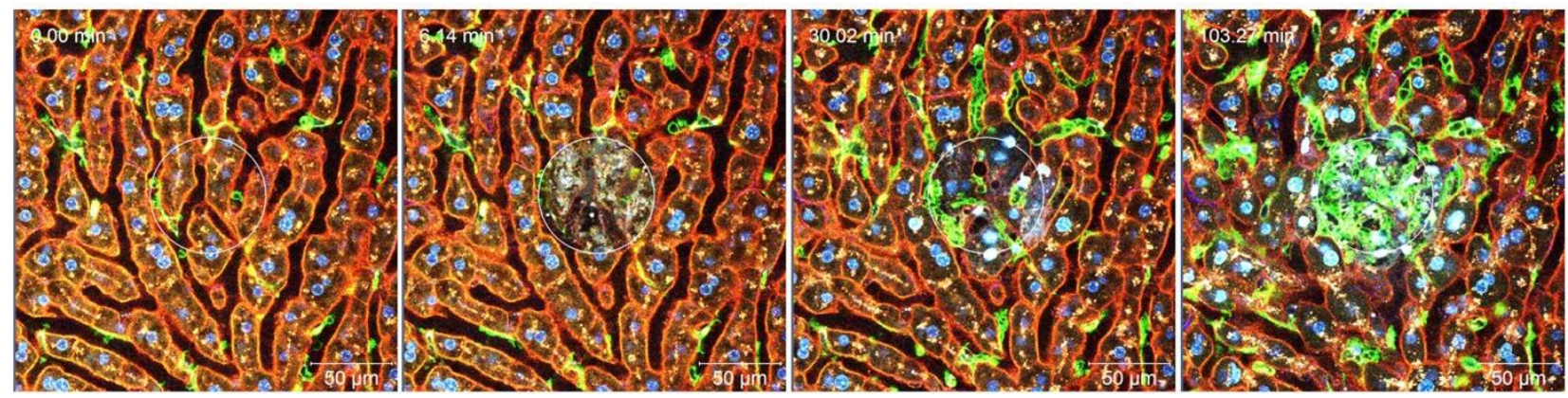

Fig. 8. Neutrophils swarming after physical liver damage. A localized physical liver damage (circle; minute 6) was induced in LysM x mT/mG mouse by high energy laser and infiltrating neutrophils (green) were imaged. 


\section{References}

Clausen BE, Burkhardt C, Reith W, Renkawitz R, Forster I (1999). Conditional gene targeting in macrophages and granulocytes using LysMcre mice. Transgenic Research, 8: 265-277.

Cohen D, Brennwald PJ, Rodriguez-Boulan E, Musch A (2004). Mammalian PAR-1 determines epithelial lumen polarity by organizing the microtubule cytoskeleton. Journal of Cell Biology, 164: 717-727.

Ding BS, Nolan DJ, Butler JM, James D, Babazadeh AO, Rosenwaks Z, Mittal V, Kobayashi H, Shido K, Lyden D, Sato TN, Rabbany SY, Rafii S (2010). Inductive angiocrine signals from sinusoidal endothelium are required for liver regeneration. Nature, 468: 310-315.

Francavilla A, Ove P, Polimeno L, Coetzee M, Makowka L, Barone M, Van Thiel DH, Starzl TE (1988). Regulation of liver size and regeneration: importance in liver transplantation. Transplant Proceedings, 20: 494-497.

Ghallab A, Celliere G, Henkel SG, Driesch D, Hoehme S, Hofmann U, Zellmer S, Godoy P, Sachinidis A, Blaszkewicz M, Reif R, Marchan R, Kuepfer L, Haussinger D, Drasdo D, Gebhardt R, Hengstler JG (2016). Model-guided identification of a therapeutic strategy to reduce hyperammonemia in liver diseases. Journal of Hepatology, 64: 860-871.

Gunawan BK, Liu ZX, Han D, Hanawa N, Gaarde WA, Kaplowitz N (2006). cJun N-terminal kinase plays a major role in murine acetaminophen hepatotoxicity. Gastroenterology, 131: 165-178.

Hoehme S, Brulport M, Bauer A, Bedawy E, Schormann W, Hermes M, Puppe V, Gebhardt R, Zellmer S, Schwarz
M, Bockamp E, Timmel T,

Hengstler JG, Drasdo D (2010).

Prediction and validation of cell alignment along microvessels as order principle to restore tissue architecture in liver regeneration. Proceedings of the National Academy of Sciences U S A, 107: 10371-10376.

Hohme S, Hengstler JG, Brulport M, Schafer M, Bauer A, Gebhardt R, Drasdo D (2007). Mathematical modelling of liver regeneration after intoxication with $\mathrm{CCl}(4)$. ChemicoBiological Interaction, 168: 74-93.

Jaeschke H, Gores GJ, Cederbaum AI, Hinson JA, Pessayre D, Lemasters JJ (2002). Mechanisms of hepatotoxicity. Toxicological Science, 65: 166-176.

Jansen PL, Ghallab A, Vartak N, Reif R, Schaap FG, Hampe J, Hengstler JG (2017). The ascending pathophysiology of cholestatic liver disease. Hepatology, 65: 722-738.

Koni PA, Joshi SK, Temann UA, Olson D, Burkly L, Flavell RA (2001). Conditional vascular cell adhesion molecule 1 deletion in mice: impaired lymphocyte migration to bone marrow. Journal of Experimental Medicine, 193: 741754.

Lee YS, Kim H, Brahim JS, Rowan J, Lee G, Dionne RA (2007). Acetaminophen selectively suppresses peripheral prostaglandin E2 release and increases $\mathrm{COX}-2$ gene expression in a clinical model of acute inflammation. Pain, 129: 279-286.

Li FC, Huang GT, Lin CJ, Wang SS, Sun TL, Lo SY, Lo W, Chiou LL, Dong CY, Lee HS (2011). Apical membrane rupture and backward bile flooding in acetaminophen- 
induced hepatocyte necrosis. Cell Death and Disease, 2: e183.

Manibusan MK, Odin M, Eastmond DA. (2007). Postulated carbon tetrachloride mode of action: a review. Journal of Environmental Science and Health, Part C: Environmental Carcinogenesis and Ecotoxicology Reviews, 25: 185209.

Marques PE, Oliveira AG, Pereira RV, David BA, Gomides LF, Saraiva AM, Pires DA, Novaes JT, Patricio DO, Cisalpino D, Menezes-Garcia Z, Leevy WM, Chapman SE, Mahecha G, Marques RE, Guabiraba R, Martins VP, Souza DG, Mansur DS, Teixeira MM, Leite MF, Menezes GB (2015). Hepatic DNA deposition drives drug-induced liver injury and inflammation in mice. Hepatology, 61: 348-360.

Martin-Belmonte F, Mostov K (2008). Regulation of cell polarity during epithelial morphogenesis. Current Opinion In Cell Biology, 20: 227234.

Mccaffrey LM, Macara IG (2009). Widely conserved signaling pathways in the establishment of cell polarity. Cold Spring Harbor Perspectives in Biology, 1: a001370.

Mederacke I, Hsu CC, Troeger JS, Huebener $\mathrm{P}, \mathrm{Mu} \mathrm{X}$, Dapito $\mathrm{DH}$, Pradere JP, Schwab RF. (2013). Fate tracing reveals hepatic stellate cells as dominant contributors to liver fibrosis independent of its aetiology. Nature Communication, 4: 2823.

Michalopoulos GK (2007). Liver regeneration. Journal of Cellular Physiology, 213: 286-300.

Michalopoulos GK (2010). Liver regeneration after partial hepatectomy: critical analysis of mechanistic dilemmas. The American Journal of Pathology, 176: 2-13.

Michalopoulos GK, Defrances MC (1997). Liver regeneration. Science, 276: 60-66.

Muzumdar MD, Tasic B, Miyamichi K, Li L, Luo L (2007). A global doublefluorescent Cre reporter mouse. Genesis, 45: 593-605.

Panbianco C, Gotta M (2011). Coordinating cell polarity with cell division in space and time. Trends in Cell Biology, 21: 672-680.

Reif R, Ghallab A, Beattie L, Gunther G, Kuepfer L, Kaye PM, Hengstler JG (2017). In vivo imaging of systemic transport and elimination of xenobiotics and endogenous molecules in mice. Archives of Toxicology, 91: 1335-1352.

Schliess F, Hoehme S, Henkel SG, Ghallab A, Driesch D, Bottger J, Guthke R, Pfaff M, Hengstler JG, Gebhardt R, Haussinger D, Drasdo D, Zellmer S (2014). Integrated metabolic spatial-temporal model for the prediction of ammonia detoxification during liver damage and regeneration. Hepatology, 60: 2040-2051.

Shivas JM, Morrison HA, Bilder D, Skop, AR (2010). Polarity and endocytosis: reciprocal regulation. Trends in Cell Biology, 20: 445452.

Starzl TE, Demetris AJ, Murase, N, Ildstad S, Ricordi C, Trucco M (1992). Cell migration, chimerism, and graft acceptance. Lancet, 339: 15791582.

Wang L, Boyer JL (2004). The maintenance and generation of membrane polarity in hepatocytes. Hepatology, 39: 892-899.

Wang Z, Sandiford S, Wu C, Li SS (2009). Numb regulates cell-cell adhesion 
and polarity in response to tyrosine kinase signalling. EMBO Journal, 28: 2360-2373.

Weber LW, Boll M, Stampfl A (2003). Hepatotoxicity and mechanism of action of haloalkanes: carbon tetrachloride as a toxicological model. Critical Reviews in Toxicology, 33: 105-36.
Woolbright BL, Jaeschke H (2017). Role of the inflammasome in acetaminophen-induced liver injury and acute liver failure. Journal of Hepatology, 66: 836-848.

Author names in bold designate shared co-first, second or senior authorship. 